
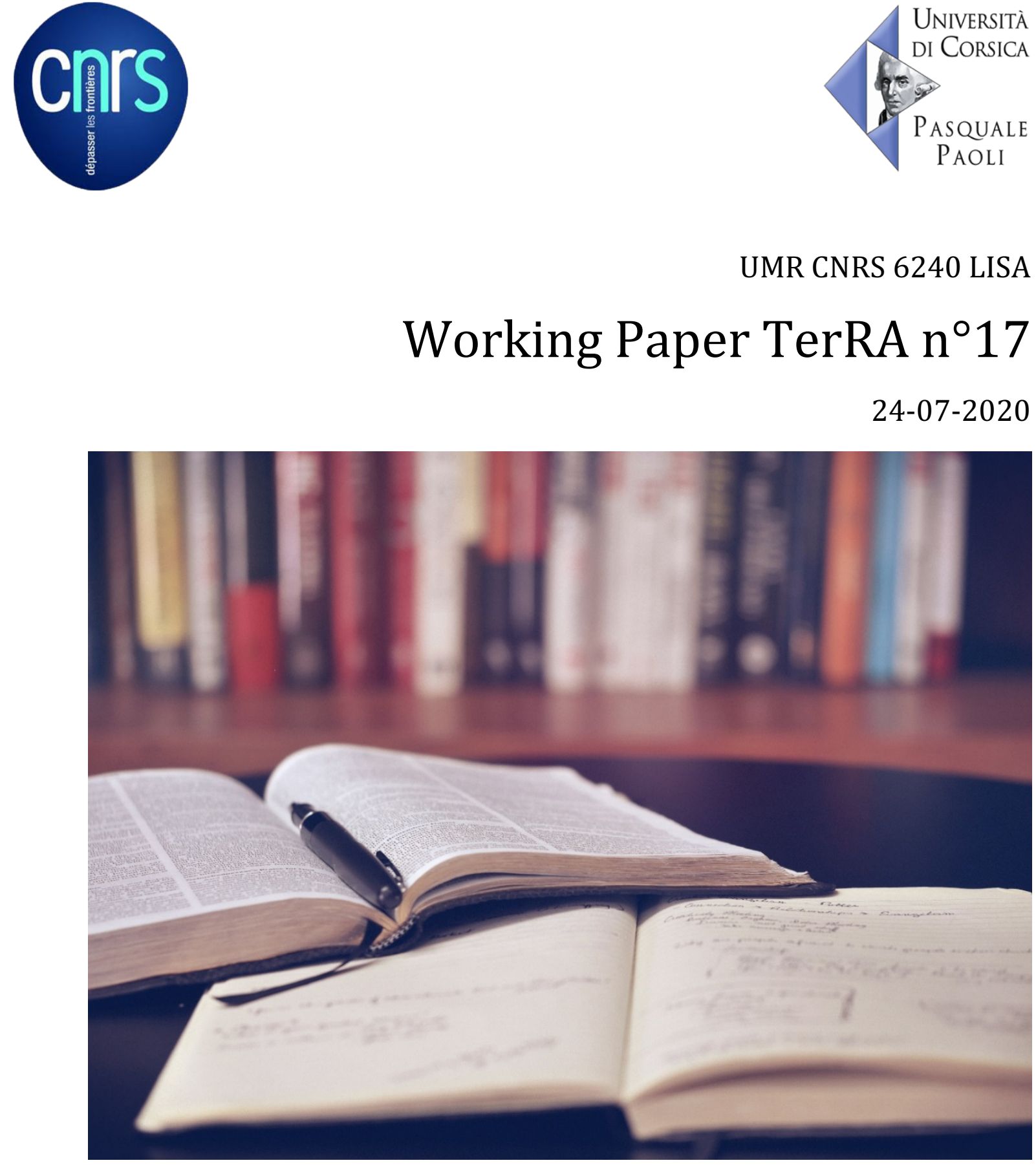

Optimal income taxation with tax avoidance and endogenous labor supply

Georges Casamatta 


\title{
Optimal income taxation with tax avoidance and endogenous labor supply
}

\author{
Georges Casamatta*
}

July 24, 2020

\begin{abstract}
We determine the optimal income tax schedule when individuals both determine endogenously their labor supply and have the possibility of avoiding paying taxes. Considering a convex concealment cost function, we propose a formula for the optimal marginal tax rate, that generalizes the standard Mirrlees formula to the case of tax avoidance. We also show that the results obtained by Casamatta (2020) in the fixed income case hold true when labor supply is endogenous: with a low enough marginal cost of avoidance, part of the taxpayers, located in the interior of the skill distribution, optimally choose to avoid taxes.
\end{abstract}

Keywords: tax avoidance, optimal income taxation.

JEL: H21, H26.

*UMR CNRS 6240 LISA, Università di Corsica Pasquale Paoli, Corte, France; email: casamatta_g@univcorse.fr 


\section{Introduction}

For a long time, the literature on optimal labor income taxation, initiated by Mirrlees (1971) and surveyed in Piketty and Saez (2013), has focused on the labor supply response to taxes. In these models, individuals react to changes in marginal tax rates by adjusting their labor supply and thus the income they earn. More recently, it has been recognized that modifications in marginal tax rates can induce individuals to alter their taxable income, not only through a change in labor supply, but also through a change in declared income (while keeping true income unchanged) (Saez et al. (2012)). This latter form of behavioral response to taxation can be illegal (tax evasion) or legal (tax avoidance). In this article, we focus on tax avoidance, that can be defined, following Piketty et al. (2014), as "changes in reported income due to changes in the form of compensation but not in the total level of compensation". More precisely, we incorporate avoidance responses by taxpayers in the standard Mirrleesian income taxation model, besides the usual labor supply response. This is all the more important that empirical evidence has pointed to fairly modest effects of taxes on labor supply (Keane (2011)), whereas the avoidance response appears stronger (Slemrod (1995), Saez et al. (2012)).

The first study that derived the optimal tax schedule while accounting for the avoidance margin was proposed by Grochulski (2007). In this model, labor supply is fixed so that individuals respond to taxes along the avoidance margin only. Considering a subadditive concealment cost function, Grochulski (2007) proves two main results. First, at the optimum with taxes, no individuals should hide income. This result is called the no-falsification theorem. Second, the optimal tax schedule is such that marginal tax rates are equal to the marginal falsification costs. Casamatta (2020) later relaxed the subadditivity assumption, by considering a convex cost function, and showed that the no-falsification theorem was not valid anymore in this setup, with part of the taxpayers displaying income lower than their true income.

None of these two articles did incorporate labor supply responses to taxation. This issue 
has been taken up in two recent papers. Piketty et al. (2014) propose a formula for the top-income marginal tax rate while considering a quasi-linear utility function (no income effects on labor supply). Huang and Rios (2016) also adopt the quasi-linear frawework and characterize the full optimal tax curve.

Our work belongs to this strand of the literature and extends it in two directions. First, we consider a general form for the utility function. Second, we allow for a concealment cost function non-differentiable at 0 , implying that some individuals adopt a corner solution for their labor supply. We develop a formula for the marginal tax rates in this general framework and contrast it with the standard Mirrlees formula. We also show that individuals located at the extreme of the skill distribution do not avoid taxes, while those located in the interior of the distribution do, thus extending the result obtained by Casamatta (2020) in the fixed income case, to the case of endogenous labor supply.

\section{Model}

Individuals differ with respect to productivity $w$, distributed according to the cumulative distribution function $F($.$) and the density f($.$) on the support \left[w_{-}, w_{+}\right]$. An individual with productivity $w$ generates income $y=w l$, where $l$ denotes his labor supply.

True income is not observable to the fiscal authority and individuals have the possibility to hide (legally) part of it to the government. This action is however costly and we denote $\phi(\Delta)$ the cost of hiding $\Delta$ euros, with $\phi(0)=0$. We allow for the possibility that individuals declare more than their true income, in which case $\Delta<0$. We assume that $\phi$ is continuous and strictly convex 1 Moreover, it is (weakly) decreasing for $\Delta<0$ and strictly increasing for $\Delta>0$. It is differentiable everywhere, except at 0 where the right-hand (resp. lefthand) derivative is positive (resp. negative). We denote these derivatives $\phi_{+}^{\prime}(\Delta)$ and $\phi_{-}^{\prime}(\Delta)$ respectively:

\footnotetext{
${ }^{1}$ Strict convexity, combined with the fact that $\phi(0) \leq 0$, implies that $\phi$ violates the subaddivity assumption in Grochulski (2007) and Landier and Plantin (2017), where a function $f$ is subadditive if and only if $f(x+y) \leq f(x)+f(y)$.

${ }^{2}$ The right- and left-hand derivatives at 0 coincide when $\phi_{+}^{\prime}(0)=\phi_{-}^{\prime}(0)=0$.
} 
The utility function, $u(c, l)$, is increasing in consumption $c$ and decreasing in labor supply $l$. Morover, we assume that indifference curves are strictly convex in the $(c, y)$ space.

\section{The social planner's program}

An individual with productivity $w$ displays income $r(w)$ to the tax administration and pays a $\operatorname{tax} T(w)$ on this income.

The social planner determines the functions $r($.$) and T($.$) that maximize social welfare,$ expressed as the sum of a concave transformation $G($.$) of individual utility levels, under$ resource and incentive constraints:

$$
(P 1) \max _{r(.), T(.)} \int G(U(w)) d F(w)
$$

st

$$
\begin{aligned}
& c(w)=y(w)-T(w)-\phi(y(w)-r(w)) \\
& U(w)=u(c(w), y(w) / w) \\
& \int T(w) f(w) d w \geq 0
\end{aligned}
$$

and

$$
U(w) \geq V\left(\hat{y}\left(w^{\prime}, w\right), w^{\prime}, w\right), \forall w, w^{\prime} \in\left[w_{-}, w_{+}\right]
$$

where equation (3) represents the Government Budget Constraint (GBC) and (4) the incentive constraints: a type $w$ individual should not want to pretend that he is of type $w^{\prime}$. 


\subsection{Optimal labor supply}

In equation (4), $\hat{y}\left(w^{\prime}, w\right)$ represents the income earned by an individual with productivity $w$ who pretends to be of type $w^{\prime}$. It is obtained by solving the program:

$$
\max _{y} V\left(y, w^{\prime}, w\right) \equiv u\left(y-T\left(w^{\prime}\right)-\phi\left(y-r\left(w^{\prime}\right)\right), y / w\right)
$$

An interior solution satisfies the first-order condition:

$$
\left(1-\phi^{\prime}\left(\hat{y}\left(w^{\prime}, w\right)-r\left(w^{\prime}\right)\right)\right) u_{c}+\frac{1}{w} u_{l}=0 .
$$

Three cases are possible: $\hat{y}\left(w^{\prime}, w\right)>r\left(w^{\prime}\right), \hat{y}\left(w^{\prime}, w\right)<r\left(w^{\prime}\right)$ or $\hat{y}\left(w^{\prime}, w\right)=r\left(w^{\prime}\right)$. The first two cases involve an interior solution. They arise respectively when:

$$
1-\phi_{+}^{\prime}(0) \geq-\frac{1}{w} \frac{u_{l}}{u_{c}}
$$

and

$$
1-\phi_{-}^{\prime}(0) \leq-\frac{1}{w} \frac{u_{l}}{u_{c}} .
$$

The corner solution $\hat{y}\left(w^{\prime}, w\right)=r\left(w^{\prime}\right)$ arises when:

$$
1-\phi_{+}^{\prime}(0)<-\frac{1}{w} \frac{u_{l}}{u_{c}}<1-\phi_{-}^{\prime}(0)
$$

\subsection{Incentive constraints}

From the incentive constraints in program $(P 1)$, every individual should report truthfully his type. Therefore:

$$
w=\arg \max _{w^{\prime}} V\left(\hat{y}\left(w^{\prime}, w\right), w^{\prime}, w\right) .
$$

The first-order condition implies:

$$
\left(-T^{\prime}(w)+r^{\prime}(w) \phi^{\prime}\right) u_{c}+\left.\frac{\partial \hat{y}}{\partial w^{\prime}}\right|_{(w, w)}\left(\left(1-\phi^{\prime}\right) u_{c}+\frac{1}{w} u_{l}\right)=0 .
$$


Two cases are then possible. In the first one, $y(w)$ is an interior solution and satisfies the first-order condition:

$$
\left(1-\phi^{\prime}(y(w)-r(w))\right) u_{c}+\frac{1}{w} u_{l}=0
$$

Using this condition, the second term in (8) vanishes and the first-order condition of program (7) becomes:

$$
-T^{\prime}(w)+r^{\prime}(w) \phi^{\prime}(y(w)-r(w))=0
$$

In the second case, $y(w)$ is a corner solution: $y(w)=r(w)$. This implies that $\partial \hat{y} /\left.\partial w^{\prime}\right|_{(w, w)}=$ $r^{\prime}(w)$ and condition (8) becomes:

$$
\left(-T^{\prime}(w)+r^{\prime}(w)\right) u_{c}+r^{\prime}(w) \frac{1}{w} u_{l}=0
$$

In the remainder of this article, we shall assume that the second-order condition of program (7) is satisfied. Violation of the second-order condition implies that a subset of individuals should be bunched at the same allocation, declaring the same level of income and paying the same amount of taxes 3

We now use the first-order condition (8) to re-express the incentive constraints (4), a standard approach in optimal taxation problems. Let differentiate (2) with respect to $w$ :

$$
\frac{d U}{d w}=y^{\prime}(w)\left(\left(1-\phi^{\prime}\right) u_{c}+\frac{1}{w} u_{l}\right)+\left(-T^{\prime}(w)+r^{\prime}(w) \phi^{\prime}\right) u_{c}-\frac{y(w)}{w^{2}} u_{l} .
$$

We again distinguish whether $y(w)$ is an interior solution or not. In the first case, the term $\left(1-\phi^{\prime}\right) u_{c}+(1 / w) u_{l}$ on the right-hand side of the above expression is equal to 0 (see (9)). In the case of a corner solution: $y^{\prime}(w)=r^{\prime}(w)$. Using (10) and (11), we find that in both cases:

$$
\frac{d U}{d w}=-\frac{y(w)}{w^{2}} u_{l}
$$

This expression, which summarizes the incentive constraints under the first-order approach,

\footnotetext{
${ }^{3}$ For a careful treatment of bunching in optimal taxation models, see Lollivier and Rochet (1983), Ebert (1992) or Boadway et al. (2000).
} 
is identical to the one encountered in the standard Mirrlees model (Mirrlees (1971), Piketty and Saez (2013)).

Taking $U(w)$ as the state variable and $r(w)$ as the control variable, the planner's program can then be restated as follows:

$$
(P 2) \max _{r(.), U(.)} \int G(U(w)) d F(w)
$$

st

$$
\int(y(w)-c(w)-\phi(y(w)-r(w))) f(w) d w \geq 0 \text { and } 12
$$

where the first constraint is the GBC, that has been re-expressed by using (1). Optimal labor income $y(w)$ and consumption $c(w)$ are determined by solving program (5) and inverting the condition $U(w)=u(c(w), y(w) / w)$.

\section{First-order conditions of the planner's program}

We form the Hamiltonian associated to program (P2) above:

$$
\mathcal{H}=(G(U(w))+\mu(y(w)-c(w)-\phi(y(w)-r(w)))) f(w)+\lambda(w) \frac{d U}{d w},
$$

where $\mu$ and $\lambda(w)$ are the multipliers associated to the GBC and the incentive constraints respectively.

The first-order conditions are:

$$
\begin{aligned}
& \frac{\partial \mathcal{H}}{\partial r}=0 \\
\Leftrightarrow & \mu\left(\phi^{\prime}+\frac{d y}{d r}\left(1-\phi^{\prime}\right)-\frac{d c}{d r}\right) f(w)+\lambda(w)\left(\frac{d y}{d r}\left(-\frac{1}{w^{2}} u_{l}-\frac{y(w)}{w^{3}} u_{l l}\right)-\frac{d c}{d r} \frac{y(w)}{w^{2}} u_{c l}\right)=0 \\
& \frac{\partial \mathcal{H}}{\partial U}=-\lambda^{\prime}(w) \\
\Leftrightarrow & -\lambda^{\prime}(w)=\left(G^{\prime}(U(w))-\mu \frac{d c}{d U}\right) f(w)-\frac{y(w)}{w^{2}} u_{c l} \frac{d c}{d U}
\end{aligned}
$$


We differentiate (2), to obtain:

$$
\begin{aligned}
\frac{d c}{d r} & =-\frac{1}{w} \frac{u_{l}}{u_{c}} \frac{d y}{d r} \\
\frac{d c}{d U} & =\frac{1}{u_{c}} .
\end{aligned}
$$

Substituting these expressions into the foc (13) and (14), these latter become:

$$
\begin{aligned}
& \mu\left(\phi^{\prime}+\frac{d y}{d r}\left(1-\phi^{\prime}+\frac{1}{w} \frac{u_{l}}{u_{c}}\right)\right) f(w)+\lambda(w) \frac{d y}{d r}\left(-\frac{1}{w^{2}} u_{l}+\frac{y(w)}{w^{3}}\left(u_{c l} \frac{u_{l}}{u_{c}}-u_{l l}\right)\right)=0 \\
& -\lambda^{\prime}(w)=\left(G^{\prime}(U(w))-\frac{\mu}{u_{c}}\right) f(w)-\lambda(w) \frac{y(w)}{w^{2}} \frac{u_{c l}}{u_{c}}
\end{aligned}
$$

Integrating (16) yields:

$$
\lambda(w)=\int_{w}^{w_{+}}\left(G^{\prime}(U(w))-\frac{\mu}{u_{c}}\right) \exp \left(-\int_{w}^{m}\left(y(s) u_{c l}\right) /\left(s^{2} u_{c}\right) d s\right) f(m) d m,
$$

where $\lambda(w) \leq 0, \lambda\left(w_{-}\right)=\lambda\left(w_{+}\right)=0$.

\section{Reported incomes at the second-best optimum}

We now establish a first feature of the optimal allocation: people should not overstate their income level.

\section{Proposition 1}

1. At the optimal (second-best) allocation: $r(w) \leq y(w)$.

2. For $\phi_{+}^{\prime}(0)$ low enough, some individuals, located in the interior of the skill distribution, optimally avoid taxes: $r(w)<y(w)$.

Proof. See appendix A.

This means that individuals either declare their true income or understate their income to the fiscal administration. Claiming to have more income then what is really earned is at the same time costly and make incentive constraints more stringent. 


\section{Marginal tax rates}

We first derive the elasticities of real and taxable income. For a given tax schedule $T_{r}(r)$, individuals choose real income $y$ and taxable income $r$ in order to maximize $u(c, l)$ subject to the budget constraint $c=y-T_{r}(r)-\phi(y-r)$. Considering a linearized tax schedule, the budget constraint becomes $c=y-\tau r-\phi(y-r)+I$, where $I$ is virtual income Substituting the budget constraint into the utility function, they solve the program:

$$
\max _{y, r} u(y-r+(1-\tau) r-\phi(y-r)+I, y / w) .
$$

In the case where both $y$ and $r$ are interior solutions, the first-order conditions write:

$$
\begin{aligned}
\left(1-\phi^{\prime}\right) u_{c}+\frac{1}{w} u_{l} & =0 \\
(1-\tau)-1+\phi^{\prime} & =0
\end{aligned}
$$

We differentiate these conditions with respect to $y, r, 1-\tau$ and $I$ to obtain:

$$
\begin{aligned}
& d y \frac{\Omega}{w^{2}}+d(1-\tau)\left(u_{c}+r(1-\tau) u_{c c}+\frac{r}{w} u_{c l}\right)+d I\left((1-\tau) u_{c c}+\frac{1}{w} u_{c l}\right)=0 \\
& d(1-\tau)+d y \phi^{\prime \prime}-d r \phi^{\prime \prime}=0,
\end{aligned}
$$

where $\Omega \equiv u_{l l}+w^{2}(1-\tau)^{2} u_{c c}+2 w(1-\tau) u_{c l}$.

Re-arranging these expressions leads to:

$$
\begin{aligned}
e_{y} & =-\frac{1-\tau}{y} \frac{w^{2}\left(u_{c}+r(1-\tau) u_{c c}+\frac{r}{w} u_{c l}\right)}{\Omega} \\
e_{r} & =\frac{1}{\phi^{\prime \prime}} \frac{1-\tau}{r}+\frac{y}{r} e_{y}=\frac{1-\tau}{r} \frac{1}{\phi^{\prime \prime}}\left(1-\phi^{\prime \prime} \frac{w^{2}\left(u_{c}+r(1-\tau) u_{c c}+\frac{r}{w} u_{c l}\right)}{\Omega}\right),
\end{aligned}
$$

where $e_{y} \equiv(d y / d(1-\tau))((1-\tau) / y)$ and $e_{r} \equiv(d r / d(1-\tau))((1-\tau) / r)$ are the elasticities of the true and declared incomes with respect to the net-of-tax rate respectively.

\footnotetext{
${ }^{4}$ This linearized tax schedule is characterized by $\tau=T_{r}^{\prime}(r)$ and $I=\tau r-T_{r}(r)$.
} 
Let define sheltered income as $z \equiv y-r$. We have:

$$
\begin{aligned}
& e_{z} \equiv \frac{d z}{d(1-\tau)} \frac{1-\tau}{z}=-\frac{1-\tau}{\phi^{\prime \prime}} \frac{1}{z} \\
& y e_{y}=r e_{r}+z e_{z} .
\end{aligned}
$$

We also determine compensated elasticities. In this purpose, we first compute, using (21) and (22), the response of labor income (true, declared and sheltered) to a change in exogenous income $I$ :

$$
\begin{aligned}
& \frac{d y}{d I}=-\frac{w^{2}(1-\tau) u_{c c}+w u_{c l}}{u_{l l}+w^{2}(1-\tau)^{2} u_{c c}+2 w(1-\tau) u_{c l}} \\
& \frac{d r}{d I}=\frac{d y}{d I} \\
& \frac{d z}{d I}=0 .
\end{aligned}
$$

We then use the Slutsky equation (expressed in elasticity form):

$$
e_{\varpi}^{c}=e_{\varpi}-\eta_{\varpi}, j=y, r, z
$$

where $\eta_{\varpi} \equiv(1-\tau)(d \varpi / d I)$, to obtain:

$$
\begin{aligned}
e_{y}^{c} & =\frac{1-\tau}{y} \frac{-w^{2} u_{c}+(y-r)\left(w^{2}(1-\tau) u_{c c}+w u_{c l}\right)}{u_{l l}+w^{2}(1-\tau)^{2} u_{c c}+2 w(1-\tau) u_{c l}} \\
e_{r}^{c} & =\frac{1-\tau}{r} \frac{1}{\phi^{\prime \prime}}\left(1-\phi^{\prime \prime} \frac{w^{2} u_{c}}{u_{l l}+w^{2}(1-\tau)^{2} u_{c c}+2 w(1-\tau) u_{c l}}\right) \\
e_{z}^{c} & =e_{z}=-\frac{1-\tau}{\phi^{\prime \prime}} \frac{1}{z} .
\end{aligned}
$$

From (15), and using (19) and (22), we can express the marginal tax rate as follows:

$$
\tau=-\frac{\lambda(w)}{\mu} \frac{1}{w f(w)} \frac{d y}{d r}\left(-\frac{1}{w} u_{l}+\frac{y(w)}{w^{2}}\left(u_{c l} \frac{u_{l}}{u_{c}}-u_{l l}\right)\right) .
$$

We re-arrange the terms of this formula, to arrive at the next proposition.

Proposition 2 The optimal marginal tax rate on declared income satisfies: 


$$
\frac{T_{r}^{\prime}(r(w))}{1-T_{r}^{\prime}(r(w))}=-\frac{u_{c} \frac{\lambda(w)}{\mu}}{1-F(w)} \frac{1-F(w)}{w f(w)}\left(1+\frac{z e_{z}}{r e_{r}}\right)\left(1+\frac{(r+z)\left(1+e_{r}-e_{r}^{c}\right)}{r e_{r}^{c}+z e_{z}^{c}}\right),
$$

where $\mu$ is the multiplier of the government budget constraint and $\lambda(w)$ is defined in (17).

Proof. See appendix B.

When true and reported incomes coincide (which correponds to the corner solution $y=r)$, the formula for the optimal marginal tax rate 32 becomes:

$$
\frac{T_{r}^{\prime}(r(w))}{1-T_{r}^{\prime}(r(w))}=-\frac{u_{c} \frac{\lambda(w)}{\mu}}{1-F(w)} \frac{1-F(w)}{w f(w)}\left(\frac{1+e_{r}}{e_{r}^{c}}\right) .
$$

This coincides with the standard Mirrlees formula (see equation (15) in Saez (2001)).

Furthermore it can be shown that formula 32 reduces to:

$$
\frac{T_{r}^{\prime}(r(w))}{1-T_{r}^{\prime}(r(w))}=-\frac{u_{c} \frac{\lambda(w)}{\mu}}{1-F(w)} \frac{1-F(w)}{w f(w)}\left(1+\frac{z e_{z}}{r e_{r}}\right)\left(1+\frac{1}{e_{y}}\right),
$$

in the case of a quasi-linear utility function (no income effects), which is close to formula (8) in Huang and Rios (2016) with $t$ set to 0, the difference coming from the way they define the social welfare function.

\section{Conclusion}

We have studied the optimal labor income taxation problem when individuals both determine their labor supply and have the possibility of avoiding paying taxes. We have shown that, with a low enough marginal cost of avoidance, part of the taxpayers, located in the interior of the skill distribution, choose to conceal part of their income to the tax administration. This result was obtained by Casamatta (2020) in the fixed income case, and is therefore robust to the introduction of endogenous labor supply. For these individuals, the optimal marginal tax rate depends both on the elasticities of true and reported incomes. For the other individuals, located at the extremes of the skill distribution, the optimal 
marginal tax formula coincides with the standard Mirrlees formula. 


\section{Appendix}

\section{A Proof of Proposition 1}

1. We evaluate the derivative of the Hamiltonian when $r(w)$ is larger than $y(w)$ :

$$
\left.\frac{\partial \mathcal{H}}{\partial r}\right|_{r(w)>y(w)}=\mu \phi_{-}^{\prime} f(w)+\left.\lambda(w) \frac{d y}{d r}\right|_{r(w)>y(w)}\left(-\frac{1}{w^{2}} u_{l}+\frac{y(w)}{w^{3}}\left(u_{c l} \frac{u_{l}}{u_{c}}-u_{l l}\right)\right) .
$$

Differentiating (9), we have:

$$
\frac{d y}{d r}=\frac{\phi^{\prime \prime} u_{c}+\left(1-\phi^{\prime}\right) \phi^{\prime} u_{c c}+\frac{1}{w} \phi^{\prime} u_{c l}}{-D_{y}},
$$

where $D_{y}$ is the derivative of $(9)$ with respect to $y$. Assuming that the second-order condition of program (5) is satisfied, $D_{y}$ is negative. We use (9) to rewrite the numerator, evaluated at $r(w)>y(w)$, as:

$$
\phi^{\prime \prime} u_{c}+\frac{1}{w} \phi_{-}^{\prime}\left(-\frac{u_{l}}{u_{c}} u_{c c}+u_{c l}\right)
$$

Indifference curves are assumed to be increasing and convex in the $(c, y)$ space. They are therefore increasing and concave in the $(y, c)$ space, implying:

$$
\begin{array}{r}
\left.\frac{d^{2} y}{d c^{2}}\right|_{u}<0 \\
\Leftrightarrow-\frac{u_{l}}{u_{c}} u_{c c}+u_{c l}<0 .
\end{array}
$$

Recalling that, by assumption, $\phi_{-}^{\prime} \leq 0$ and $\phi^{\prime \prime}>0$, we obtain $\partial y /\left.\partial r\right|_{r(w)>y(w)}>0$.

Finally, convexity of the indifference curves in the $(c, y)$ space implies $u_{c l} u_{l} / u_{c}-u_{l l}>0$. Recalling that $\lambda(w) \leq 0$, we can conclude that $\partial \mathcal{H} /\left.\partial r\right|_{r(w)>y(w)}<0$, meaning that the social planner has no incentive to increase $r(w)$ above $y(w)$.

2. Similar arguments can be developed to prove that $\partial \mathcal{H} /\left.\partial r\right|_{r(w)} \nearrow_{y(w)}<0$ when $\phi_{+}^{\prime}(0)$ 
is low enough:

$$
\left.\frac{\partial \mathcal{H}}{\partial r}\right|_{r(w) \nearrow y(w)}=\mu \phi_{+}^{\prime}(0) f(w)+\left.\lambda(w) \frac{d y}{d r}\right|_{r(w) \nearrow y(w)}\left(-\frac{1}{w^{2}} u_{l}+\frac{y(w)}{w^{3}}\left(u_{c l} \frac{u_{l}}{u_{c}}-u_{l l}\right)\right) .
$$

When $\phi_{+}^{\prime}(0) \rightarrow 0$, the first term on the right-hand side vanishes. Moreover, from the discussion above, the last term between parenthesis is positive. Because $\lambda$ is strictly negative for individuals with $w \in\left(w_{-}, w_{+}\right)$, it remains to be shown that $d y /\left.d r\right|_{r(w) \nearrow y(w)}$ is positive:

$$
\left.\frac{d y}{d r}\right|_{r(w) \nearrow y(w)}=\frac{\phi^{\prime \prime} u_{c}+\frac{1}{w} \phi_{+}^{\prime}(0)\left(-\frac{u_{l}}{u_{c}} u_{c c}+u_{c l}\right)}{-D_{y}>0} .
$$

Recalling that $\phi^{\prime \prime}>0$, this expression is strictly positive when $\phi_{+}^{\prime}(0) \rightarrow 0$.

\section{B Proof of Proposition 2}

1. We first prove that:

$$
\left.\frac{y(w)}{w^{2}}\left(u_{c l} \frac{u_{l}}{u_{c}}-u_{l l}\right)\right)=(1-\tau) u_{c} \frac{1+e_{y}-e_{y}^{c}}{\frac{r}{y} e_{r}^{c}-\frac{r}{y} e_{r}+e_{y}} .
$$

From (23):

$$
\begin{aligned}
1+e_{y} & =\frac{u_{l l}+w^{2}(1-\tau)^{2} u_{c c}+2 w(1-\tau) u_{c l}-w^{2}(1-\tau) \frac{u_{c}}{y}-\frac{r}{y} w^{2}(1-\tau)^{2} u_{c c}-\frac{r}{y} w(1-\tau) u_{c l}}{\Omega} \\
& =\frac{u_{l l}+\left(1-\frac{r}{y}\right) w^{2}(1-\tau)^{2} u_{c c}+\left(2-\frac{r}{y}\right) w(1-\tau) u_{c l}-w^{2}(1-\tau) \frac{u_{c}}{y}}{\Omega} .
\end{aligned}
$$

Using (28):

$$
\begin{aligned}
1+e_{y}-e_{y}^{c} & =\frac{u_{l l}+\left(1-\frac{r}{y}\right) w^{2}(1-\tau)^{2} u_{c c}+\left(2-\frac{r}{y}\right) w(1-\tau) u_{c l}-w^{2}(1-\tau) \frac{u_{c}}{y}}{\Omega} \\
& -\frac{-w^{2}(1-\tau) \frac{u_{c}}{y}+\left(1-\frac{r}{y}\right)\left(w^{2}(1-\tau)^{2} u_{c c}+w(1-\tau) u_{c l}\right)}{\Omega} \\
& =\frac{u_{l l}+w(1-\tau) u_{c l}}{\Omega} .
\end{aligned}
$$


Using (24) and (29):

$$
\begin{aligned}
\frac{r}{y} e_{r}^{c}-\frac{r}{y} e_{r}+e_{y} & =\frac{r}{y} e_{r}^{c}-\frac{1}{\phi^{\prime \prime}} \frac{1-\tau}{y} \\
& =-\frac{w^{2} u_{c}}{\Omega} \frac{1-\tau}{y} .
\end{aligned}
$$

Combining (35) and (36):

$$
\begin{aligned}
\frac{1+e_{y}-e_{y}^{c}}{\frac{r}{y} e_{r}^{c}-\frac{r}{y} e_{r}+e_{y}} & =\frac{u_{l l}+w(1-\tau) u_{c l}}{-w^{2} u_{c}} \frac{y}{1-\tau} \\
& =\frac{\frac{u_{l}}{u_{c}} u_{c l}-u_{l l}}{w^{2} u_{c}} \frac{y}{1-\tau} .
\end{aligned}
$$

Re-arranging the last expression leads to (34).

2. We then prove that:

$$
\frac{d y}{d r}=\frac{y e_{y}}{r e_{r}}
$$

From 21):

$$
\frac{d y}{d r}=T^{\prime \prime} \frac{u_{c}+r(1-\tau) u_{c c}+\frac{r}{w} u_{c l}}{(1-\tau)^{2} u_{c c}+\frac{2(1-\tau)}{w} u_{c l}+\frac{1}{w^{2}} u_{l l}}
$$

Using (23):

$$
\frac{d y}{d r}=-T^{\prime \prime} \frac{y e_{y}}{1-\tau}
$$

Using (24):

$$
\begin{aligned}
\frac{1-\tau}{\phi^{\prime \prime}} & =r e_{r}-y e_{y} \\
\Leftrightarrow & \frac{T^{\prime \prime}}{1-\tau}=\frac{T^{\prime \prime}}{\phi^{\prime \prime}} \frac{1}{r e_{r}-y e_{y}} .
\end{aligned}
$$

Using (38):

$$
\frac{d y}{d r}=-\frac{T^{\prime \prime}}{\phi^{\prime \prime}} \frac{y e_{y}}{r e_{r}-y e_{y}} .
$$


From (22):

$$
\begin{aligned}
\frac{d y}{d r} & =1+\frac{T^{\prime \prime}}{\phi^{\prime \prime}} . \\
\Leftrightarrow & \frac{T^{\prime \prime}}{\phi^{\prime \prime}}=\frac{d y}{d r}-1 .
\end{aligned}
$$

Substituting into (39):

$$
\begin{aligned}
\frac{d y}{d r} & =\left(1-\frac{d y}{d r}\right) \frac{y e_{y}}{r e_{r}-y e_{y}} . \\
\Leftrightarrow & \frac{d y}{d r}=\frac{y e_{y}}{r e_{r}} .
\end{aligned}
$$

3. We use (19) and (20), to obtain:

$$
-\frac{1}{w} u_{l}=(1-\tau) u_{c}
$$

Starting from (31), and using (34), (37), and (40), we arrive at:

$$
\frac{T_{r}^{\prime}(r(w))}{1-T_{r}^{\prime}(r(w))}=-\frac{\lambda(w)}{\mu} \frac{u_{c}}{w f(w)} \frac{y e_{y}}{r e_{r}}\left(1+\frac{1+e_{y}-e_{y}^{c}}{\frac{r}{y} e_{r}^{c}-\frac{r}{y} e_{r}+e_{y}}\right) .
$$

From (25):

$$
\frac{y e_{y}}{r e_{r}}=1+\frac{z e_{z}}{r e_{r}} .
$$

Moreover, it can be shown easily, using (27) and (26), that $e_{y}-e_{y}^{c}=e_{r}-e_{r}^{c}$. We finally multiply the denominator and numerator of

$$
\frac{1+e_{y}-e_{y}^{c}}{\frac{r}{y} e_{r}^{c}-\frac{r}{y} e_{r}+e_{y}}
$$

by $y=r+z$ and we use (25), to arrive at (32). 


\section{References}

Boadway, R., K. Cuff, and M. Marchand (2000, October). Optimal Income Taxation With Quasi-Linear Preferences Revisited. Journal of Public Economic Theory 2(4), 435-460. [3]

Casamatta, G. (2020, May). Optimal income taxation with tax avoidance. Working Paper TerRA 15. (document), 1, 7

Ebert, U. (1992, October). A reexamination of the optimal nonlinear income tax. Journal of Public Economics 49(1), 47-73. 3

Grochulski, B. (2007). Optimal Nonlinear Income Taxation with Costly Tax Avoidance. Economic Quarterly 93(1), 77-109. 1. 1

Huang, J. and J. Rios (2016, December). Optimal tax mix with income tax non-compliance. Journal of Public Economics 144, 52-63. 1, 6

Keane, M. P. (2011, December). Labor Supply and Taxes: A Survey. Journal of Economic Literature 49(4), 961-1075. 1

Landier, A. and G. Plantin (2017, July). Taxing the Rich. Review of Economic Studies $84(3), 1186-1209.1$

Lollivier, S. and J.-C. Rochet (1983, December). Bunching and second-order conditions: A note on optimal tax theory. Journal of Economic Theory 31(2), 392-400. 3

Mirrlees, J. A. (1971, April). An Exploration in the Theory of Optimum Income Taxation. The Review of Economic Studies 38(2), 175-208. 1, 3.2

Piketty, T. and E. Saez (2013). Optimal Labor Income Taxation. In Handbook of Public Economics, Volume 5, pp. 391-474. Elsevier. 1, 3.2 
Piketty, T., E. Saez, and S. Stantcheva (2014, February). Optimal Taxation of Top Labor Incomes: A Tale of Three Elasticities. American Economic Journal: Economic Policy 6(1), 230-271. 1

Saez, E. (2001). Using Elasticities to Derive Optimal Income Tax Rates. The Review of Economic Studies 68(1), 205-229. 6

Saez, E., J. Slemrod, and S. H. Giertz (2012). The Elasticity of Taxable Income with Respect to Marginal Tax Rates: A Critical Review. Journal of Economic Literature 50(1), 3-50. 1]

Slemrod, J. (1995, August). High-Income Families and the Tax Changes of the 1980s: The Anatomy of Behavioral Response. Technical Report w5218, National Bureau of Economic Research, Cambridge, MA. 1] 